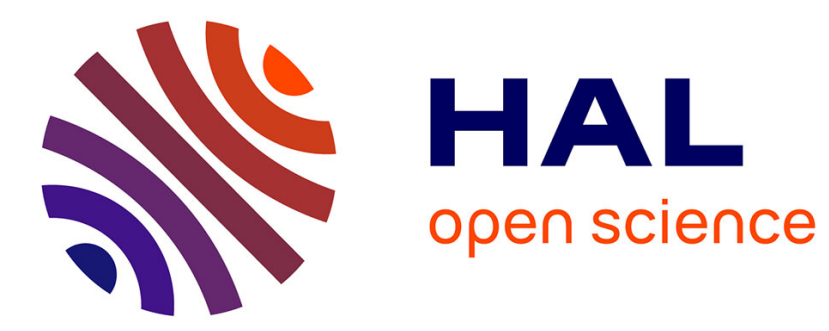

\title{
Contrasting bird communities along production gradients of crops and livestock in French farmlands
}

Camille Dross, Karine Princé, Frédéric Jiguet, Muriel Tichit

\section{To cite this version:}

Camille Dross, Karine Princé, Frédéric Jiguet, Muriel Tichit. Contrasting bird communities along production gradients of crops and livestock in French farmlands. Agriculture, Ecosystems and Environment, 2018, 253, pp.55 - 61. 10.1016/j.agee.2017.10.025 . hal-01634656

\section{HAL Id: hal-01634656 \\ https://hal.sorbonne-universite.fr/hal-01634656}

Submitted on 14 Nov 2017

HAL is a multi-disciplinary open access archive for the deposit and dissemination of scientific research documents, whether they are published or not. The documents may come from teaching and research institutions in France or abroad, or from public or private research centers.
L'archive ouverte pluridisciplinaire $\mathbf{H A L}$, est destinée au dépôt et à la diffusion de documents scientifiques de niveau recherche, publiés ou non, émanant des établissements d'enseignement et de recherche français ou étrangers, des laboratoires publics ou privés. 


\title{
Contrasting bird communities along production gradients of crops and livestock in French farmlands
}

\author{
Camille Dross $^{\mathrm{a}, *}$, Karine Princé ${ }^{\mathrm{c}, \mathrm{d}}$, Frédéric Jiguet $^{\mathrm{c}}$, Muriel Tichit ${ }^{\mathrm{a}}$ \\ a UMR SADAPT, INRA, AgroParisTech, Université Paris-Saclay, 75005, Paris, France \\ c Centre d'Ecologie et des Sciences de la Conservation (CESCO UMR7204), Sorbonne Universités, MNHN, CNRS, UPMC, CP51, 55 rue Buffon, 75005, Paris, France \\ d Department of Forest and Wildlife Ecology, University of Wisconsin-Madison, Madison, WI 53706, USA
}

Keywords:

Agricultural production

Farmland birds

Specialization

Trophic structure

\begin{abstract}
A B S T R A C T
Impacts on birds of intensive management practices and of landscape simplification have been widely studied, but there is a lack of knowledge about impacts on birds of landscapes associated with intensive livestock production. The objective of this work was to investigate changes in several bird community descriptors along different production gradients. Production of arable crops and from grazing livestock was computed over French agroecosystems and expressed in terms of edible energy. Using data from the French Breeding Bird Survey along with data from national agricultural statistics, we modeled the relationship between production and five bird community descriptors, namely, community trophic index, community specialization index, and three groupspecific species richness indices. Bird communities were shaped by two production gradients. Along a gradient of increasing crop production, we observed a shift from locally species-diverse communities dominated by generalist or grassland specialist species towards species-poor communities dominated by granivorous species specialized in arable habitats (all p-values $\leq 0.002$ ). Second, we observed a shift towards homogenized communities dominated by generalists along a gradient of increasing livestock production ( $p$-values $\leq 0.001$ ). Our research highlights the need to consider crop and livestock separately when investigating their impacts on biodiversity. It also hints towards the need for differentiated strategies to protect farmland birds in crop regions and in livestock regions.
\end{abstract}

\section{Introduction}

Man appropriates a substantial share of the planet's ice-free land surface (Ramankutty et al., 2008) and of the terrestrial net primary production (Haberl et al., 2007; Krausmann et al., 2013), in particular through agriculture. In Western Europe, agricultural intensification through both intensive management practices and landscape simplification has made it possible to increase food production considerably in the second half of the twentieth century, but it has had detrimental effects on Europe's biodiversity (Donald et al., 2001, 2006; Le Féon et al., 2010; Storkey et al., 2012).

Impacts on birds of intensive management practices have been well studied. Results show contrasted responses for different bird groups, with "loser" and "winner" species (Phalan et al., 2011; Teillard et al., 2015). Habitat specialists are generally the most vulnerable to humaninduced disturbances (Devictor et al., 2008), as can be shown using the habitat species specialization index (hereafter SSI) proposed by Julliard et al. (2004). This index discriminates between species with much higher abundances in one particular habitat than anywhere else, which have a high SSI and can be called habitat specialists, and species with equal abundances in most habitats, which have a low SSI and are referred to as habitat generalists. Farmland habitat specialist species, which are specialists of farmland habitat, are probably the most vulnerable to intensive management practices because they spend most of their time in farmland and rely mainly on resources and habitat found there. Doxa et al. (2012) have observed a decline of farmland specialist abundances only in highly intensified agriculture areas and not in High Nature Value Farmland. In arable regions, the most specialized species are the most vulnerable to pesticide applications (Filippi-Codaccioni et al., 2010a), and the mean specialization of the bird community is negatively correlated with herbicide doses (Chiron et al., 2014). Chiron et al. (2014) have also observed a positive relationship between herbicide doses and bird species richness. This result could be due to generalist species, which are generally bad competitors in agricultural landscapes, colonizing habitats that have been deserted by specialist species following an herbicide treatment.

Impacts of landscape intensification of crop production (Tscharntke et al., 2005) or of extensive grassland-based livestock production have

\footnotetext{
* Corresponding author at: UMR 1048 SADAPT, 16 rue Claude Bernard, 75005 Paris, France.

E-mail addresses: camille.dross.2008@polytechnique.org (C. Dross), karine.prince@gmail.com (K. Princé), fjiguet@mnhn.fr (F. Jiguet), muriel.tichit@agroparistech.fr (M. Tichit).
} 
been widely studied. Landscape simplification, that is to say, the increase of the extent of cropland and the size of fields, is generally considered to have a positive impact on farmland specialists, and a negative impact on all other species (Chiron et al., 2014; FilippiCodaccioni et al., 2010a; Jeliazkov et al., 2016). Recently, Teillard et al. (2014) have split the farmland specialist species into three groups according to their within-farmland specialization, making it possible to show that specialist species benefit from a higher extent of their habitat within farmland. Thus, arable specialists thrive in regions specialized in crops, whereas grassland specialists are favored in regions where grasslands are present. Conversely, habitat generalist species and indeed a majority of species depend on a heterogeneous mosaic of land uses, and there are far fewer species in simplified landscapes. Little is known about the impacts on birds of landscapes associated with intensive livestock production, although a recent study by Dross et al. (2017) has failed to detect covariations between bird biodiversity and livestock production.

The objective of this work was to investigate changes in several bird community characteristics along gradients of increasing crop or livestock production. First, we estimated crop production, meat and milk production across French farmlands. Then, we computed the mean specialization index of the community, the mean trophic index and three group-specific species richness (SR) indices to capture the shifts in composition associated with production. Finally, we used generalized additive mixed models to assess the relationship between production and each bird community descriptor. In particular, we tested the following mutually exclusive hypotheses:

H1. Specialist species as winner species, possibly because the extent of their habitat increases as more land is dedicated to production.

We expected a shift from generalists to arable specialists along a crop production gradient, as well as a shift from generalists to grassland specialists along a livestock production gradient. We expected both shifts to be accompanied by an increase in the community specialization index.

H2. Specialist species as loser species, possibly because they are more vulnerable to intensive management practices than generalist species.

Along both production gradients, we expected an increase in generalist species richness, and a decrease in the community specialization index and any specialist species richness.

\section{Material and methods}

\subsection{Agricultural data}

We focused on agricultural ecosystems in France, and more particularly on land dedicated to arable crops or grazing livestock, i.e., cattle, sheep, and goats. Hereafter, the area of this land is referred as the agricultural area. These production systems produce three main types of products which are crop products, meat, and milk. We computed two production metrics: arable crop production (hereafter crop production) and production from grazing livestock (hereafter livestock production), both being expressed in terms of edible energy. Since our focus was on the agricultural area and on bird communities within this agricultural area, we divided these metrics by the agricultural area.

We computed production for 244 Small Agricultural Regions (SARs), which had a mean area of $1418 \mathrm{~km}^{2}$. French SARs are consistent with administrative boundaries and have homogeneous soilclimatic conditions and agricultural production systems. They have been used with success to model bird community responses to landscape composition (Teillard et al., 2014). Data on the volume of milk production, and on the mass of meat or crop production, were derived from 2010 annual statistics. Since this data set was available only at the Nomenclature of Territorial Units for Statistics (NUTS) 3 level, which have a mean area of circa $5800 \mathrm{~km}^{2}$, it was necessary to estimate these data at the SAR level. Assuming crop yield and animal productivity to be uniform within each NUTS 3 level made it possible to do this using SAR-level data on crop surfaces and livestock numbers obtained from the 2010 Agricultural Census. The estimations thus obtained were then converted into edible energy using conversion coefficients (FAO, 2003; ANSES, 2013). Information regarding the estimation process and validation can be found in Dross et al. (2017). The maps of computed production are available in Appendix A in Supplementary materials.

\subsection{Bird data}

We focused on common birds, which are widespread and commonly surveyed (Jiguet et al., 2012). They are also considered an accurate gauge for measuring environmental health (Gregory and van Strien, 2010) and are generally sensitive to change (Jiguet et al., 2007). Also, because they are rather high in the food chain, they may reflect changes occurring in other taxa (Wilson et al., 1999). We focused on 74 common bird species, listed in Table C-1 in Supplementary materials. Some species were classified as habitat generalist or farmland specialist species following Jiguet et al. (2012). Farmland specialist species could be further classified into arable specialist or grassland specialist species following Teillard et al. (2014).

All bird data were taken from the French Breeding Bird Survey (FBBS). The FBBS is a nationwide, standardized monitoring program conducted by skilled volunteer ornithologists who count breeding birds in randomly selected sites each spring (Jiguet et al., 2012). Each FBBS site consists of a $2 \times 2 \mathrm{~km}$ square, in which 10 point counts are evenly distributed and placed no less than $200 \mathrm{~m}$ apart. All point counts are unbounded, and observers record every individual bird either heard or seen, along with the distance of contact ( $<25 \mathrm{~m}, 25-100 \mathrm{~m},>100 \mathrm{~m}$ ), during a 5-min survey conducted twice every spring (before and after May the 8 th, at least 4 weeks apart).

We computed five bird community descriptors: two trait-based metrics and three metrics based on particular species groups. The latter metrics were the number of generalist species (generalist SR), the number of grassland specialist species, and the number of arable specialist species. The two trait-based metrics were the Community Trophic Index (CTI) (Princé et al., 2013; Teillard et al., 2015) and the Community Specialization Index (CSI) (Devictor et al., 2008). The CTI discriminates between communities with more granivorous species, which are at a low trophic level, and communities with more insectivorous and carnivorous species, which are at a high trophic level. It is computed as the mean of the species trophic indices (STI) of the species present weighted by the proportion of each species in the community. Species trophic indices are determined on the basis of the species' diet, specifically, the proportions of plants, invertebrates, and vertebrates that the species consumes (based on Perrins and Cramp, 1998). The CSI differentiates between communities dominated by habitat specialists, which are at a high specialization level, and highly disturbed communities, which are dominated by generalists and are at a low specialization level (Devictor et al., 2008). It is computed as the mean of the species specialization indices (SSI) of the species in the community. Species' STI and SSI are given in Supplementary Tables B.1 to B.4.

We computed all five bird community descriptors for 516 sites of the FBBS that had a least half their area in agricultural land (Fig. 1a and b). These FBBS sites were identified by computing the share of area usable for grazing or under arable or fodder crop cultivation for each FBBS site in databases provided by Sausse et al. (2015). As agricultural activities are relatively slow changing, and since our aim was not to study potential temporal trends or inter-annual variability of the measured metrics, we used bird data collected from 2010 to 2013 and averaged retained metrics for each site across all sampled years in this period.

For each year and each site, we computed abundances for each species in 3 steps: 


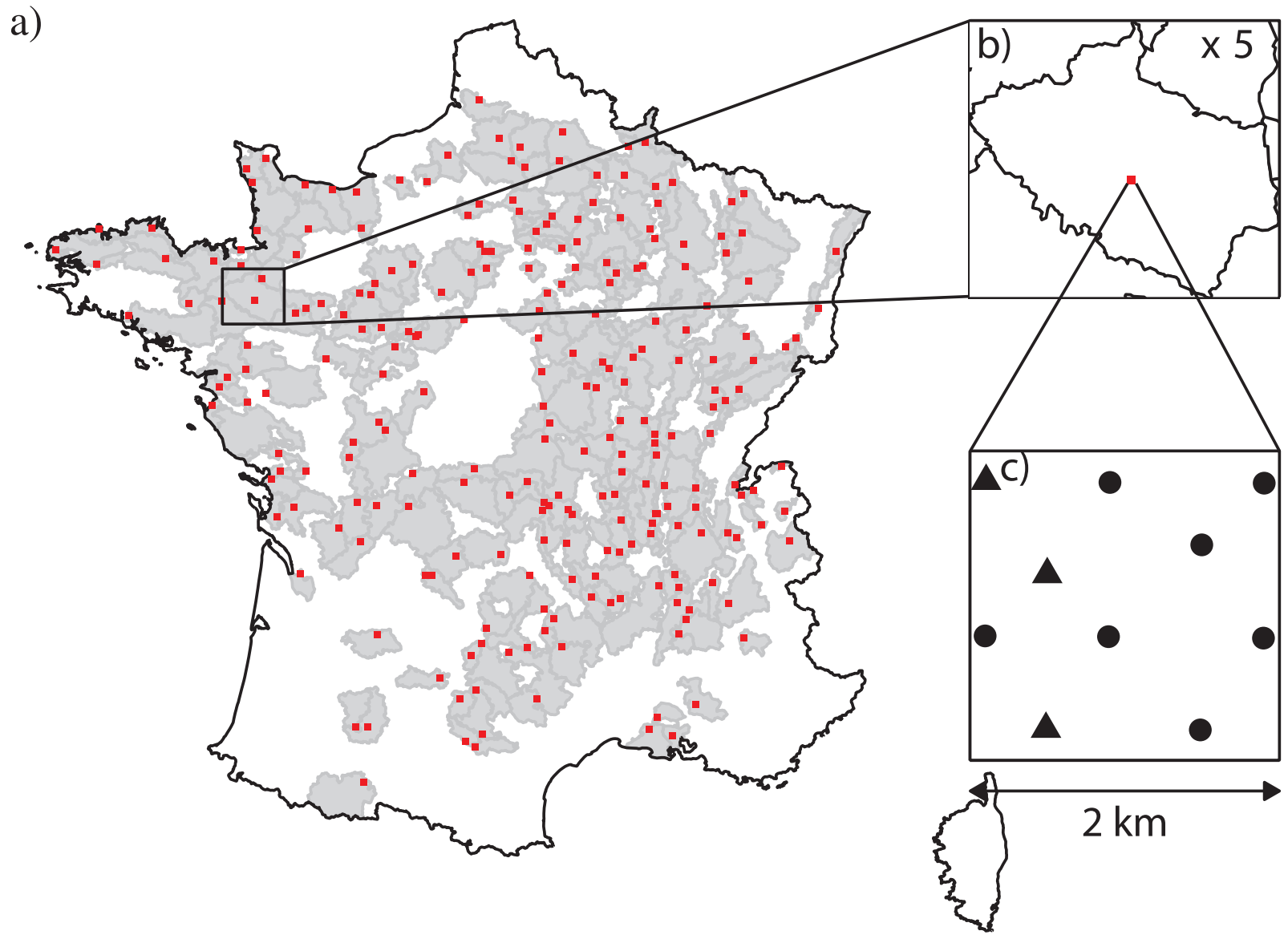

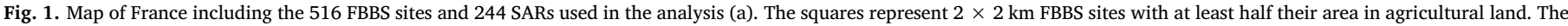

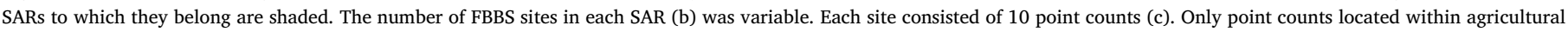

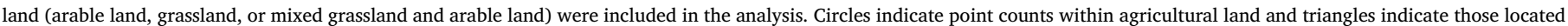
elsewhere.

1. We retained the maximum abundance over the two yearly surveys for each point count, except for three species which generally have not completed their spring migration at the time of the first yearly visit. For these species, we considered only counts from the second visit (Princé et al., 2015).

2. For less than $0.1 \%$ of point counts, more than ten individuals of a single species were recorded during a single 5-min point count. As it is difficult for observers to count accurately large numbers of similar individuals, we only took into account the ten first individuals of each species observed during a single point count.

3. We summed abundances over all the point counts located within farmland habitat (Fig. 1c). We retained the number of point counts located within farmland habitat, hereafter referred to as the number of point counts, for use as a predictor in the models.

We then computed CTI, CSI and the three group-specific species richness indices for each year and each site. Finally, we averaged each bird community descriptor across all years for each site. The density curves and basic descriptive statistics for all five metrics can be found in Appendix B in Supplementary materials.

\subsection{Statistical analyses}

We investigated the relationship between each bird community descriptor and production using generalized additive mixed models (GAMM). GAMMs are similar to generalized linear mixed models, but they are able to handle nonlinear relationships between response and predictor variables (Wood 2006; Zuur et al., 2009). The bird community descriptors computed at each FBBS site within the SARs were considered as the dependent variable, whereas production variables computed at the SAR level were defined as predictor variables. In order to consider sites within a SAR as repeated measures, we included a SAR random effect. Since we suspected that bird communities may also be impacted by local climatic conditions, we included as covariates mean temperature and rainfall at each site during the months of April and May of the years the data was collected. The number of point counts in each FBBS site was integrated as a covariate to account for the varying sampling effort between FBBS sites. We also included two-dimensional spline on geographical coordinates to account for trends across larger geographical distances (Dormann et al., 2007). We assumed a Gaussian distribution for all dependent variables. Prior to all analyses, we log-transformed CTI and CSI to ensure normality, and we mean-centered each predictor variable and divided it by its standard deviation to ensure the models ran smoothly. All spline functions had $8^{\circ}$ of freedom. For each bird community descriptor, the full model was:

Birdcommunitydescriptor $\sim s$ (numberofpointcounts)

$$
\begin{aligned}
& +s \text { (geographicalcoordinates })+s \text { (livestockproduction }) \\
& +s(\text { cropproduction })+\text { elevation }+ \text { rainfall }+ \text { temperature }+(1 \mid S A R)
\end{aligned}
$$

We then used the MuMIn package (Barton, 2014) and the maximum likelihood (ML) approach to compute all sub-models of this full model. Importance of each predictor variable was then computed as the sum of 'Akaike weights' overall models including it. For each bird community descriptor, we selected the best GAMM based on AICc criterion. Finally, we re-computed this best model with the restricted maximum 
Table 1

Relative importance of predictor variables with regards to each bird community descriptor. N, number; Geog. coord., geographical coordinates; Crop. prod., crop production; Liv. prod., livestock production; Temp., temperature; Elev., elevation; Rain., Rainfall; SR, species richness; CTI, community trophic index; CSI, community specialization index.

\begin{tabular}{|c|c|c|c|c|c|c|c|}
\hline $\begin{array}{l}\text { Community } \\
\text { descriptor }\end{array}$ & $\begin{array}{l}\mathrm{N} \text { of } \\
\text { point } \\
\text { counts }\end{array}$ & $\begin{array}{l}\text { Geog. } \\
\text { coord. }\end{array}$ & $\begin{array}{l}\text { Crop } \\
\text { prod. }\end{array}$ & Liv. Prod. & Temp. & Elev. & Rain. \\
\hline Generalist SR & 1 & 1 & 0.94 & 0.97 & 0.36 & 1 & 0.69 \\
\hline $\log (\mathrm{CTI})$ & 0.71 & 1 & 1 & 0.39 & 0.34 & 0.99 & 0.50 \\
\hline $\begin{array}{l}\text { Grassland } \\
\text { specialist } \\
\text { SR }\end{array}$ & 1 & 1 & 1 & 0.11 & 0.26 & 0.28 & 0.27 \\
\hline $\log (\mathrm{CSI})$ & 0.91 & 0.93 & 0.95 & 1 & 0.39 & 0.84 & 0.96 \\
\hline $\begin{array}{l}\text { Arable } \\
\text { specialist } \\
\text { SR }\end{array}$ & 1 & 0.90 & 1 & 0.96 & 0.33 & 0.31 & 0.56 \\
\hline
\end{tabular}

likelihood (REML) approach, and we checked a posteriori that there was no autocorrelation in the residuals by plotting the variograms and computing Moran's I autocorrelation coefficient. The model selection tables and results of the models with very small delta AICc (delta AICc $<6$ ) are available in Appendices C and D in Supplementary materials.

All artwork was produced using ggplot2 (Wickham, 2009).

\section{Results}

For all bird community descriptors, crop production was an important predictor (relative importance $\mathrm{RI} \geq 0.94$, Table 1) and was selected in the best model (Table 2, Fig. 2a). Generalist species richness, community trophic index, and grassland specialist species richness were all negatively associated with crop production (Fig. 2a and Supplementary Figures D.1, D.3 and D.5), whereas community specialization index and arable specialist species richness were both positively associated with crop production (Fig. 2a and Supplementary Figures D.7 and D.9).

Livestock production was an important predictor only for generalist species richness, for arable specialist species richness and for the community specialization index $(\mathrm{RI} \geq 0.96$, Table 1$)$. For these three bird community descriptors, livestock production was present in the best model (Table 2, Fig. 2b). Community specialization index and arable specialist species richness were negatively associated with livestock production, whereas the relationship between generalist species richness and livestock production was positive and saturating (Fig. 2b).

The number of point counts was of utmost importance for predicting the number of bird species in any particular group $(\mathrm{RI}=1$ for all 3 groups), clearly suggesting that observers did not extensively survey all species present in the $2 \mathrm{~km} * 2 \mathrm{~km}$ site.

The two-dimensional spline on geographical coordinates had

Table 2

Estimated degrees of freedom and approximate significance of smooth terms for crop and livestock production in the GAMMs selected by the model selection process (best models). SR, species richness; CTI, community trophic index; CSI, community specialization index; edf, estimated degrees of freedom; F, approximate F statistic; $\mathrm{p}$, approximate $p$-value; R2, $\mathrm{R}^{2}$ figure. Empty cells mean the predictor was not selected by the model selection process.

\begin{tabular}{|c|c|c|c|c|c|c|c|}
\hline \multirow[t]{2}{*}{ Community descriptor } & \multicolumn{3}{|c|}{ Crop production } & \multicolumn{3}{|c|}{ Livestock production } & \multirow[t]{2}{*}{$\mathrm{R} 2$} \\
\hline & edf & $\mathrm{F}$ & $\mathrm{p}$ & edf & $\mathrm{F}$ & $\mathrm{p}$ & \\
\hline Generalist SR & 1.0 & 9.61 & 0.002 & 3.3 & 6.07 & $<0.001$ & 0.364 \\
\hline $\log (\mathrm{CTI})$ & 1.0 & 40.4 & $<0.001$ & & & & 0.342 \\
\hline $\begin{array}{l}\text { Grassland specialist } \\
\text { SR }\end{array}$ & 1.0 & 84.8 & $<0.001$ & & & & 0.474 \\
\hline $\log (\mathrm{CSI})$ & 1.0 & 11.5 & $<0.001$ & 1.0 & 22.1 & $<0.001$ & 0.326 \\
\hline Arable specialist SR & 2.5 & 8.87 & $<0.001$ & 1.0 & 10.5 & 0.001 & 0.386 \\
\hline
\end{tabular}

relatively high to very high relative importance $(0.9 \leq \mathrm{RI} \leq 1$, Table 1), confirming the existence of major geographical trends. Conversely, temperature and rainfall often had lower relative importance (Table 1). Since we did not check correlations between rainfall, elevation, temperature, and geographic coordinates, we suspect these variables to be linked together. It would, therefore, be inadvisable to dissociate the impact of one of these variables from that of the others. We do not discuss further the results concerning these variables.

\section{Discussion}

This study investigated covariations of five bird descriptors with agricultural production. As we have seen, bird communities in French farmlands change along two main production gradients. First, we observed a shift from species-diverse communities dominated by generalists or by grassland specialists to species-poor highly specialized communities along a crop production gradient. Second, we observed a shift towards generalist-dominated communities along a livestock production gradient. These results suggest that the mechanisms underlying the covariation of bird communities with agricultural production are probably different in regions specialized in crops than in regions specialized in livestock.

\subsection{Crop production and the specialization of bird communities}

For crop production, our results were consistent with H1, which predicted a shift from generalists to arable specialists along a crop production gradient. Since crop production is highly correlated with the share of agricultural area under crop cultivation over French agroecosystems and at SAR scale (Dross et al., 2017), it is likely that this shift is essentially driven by the extent of arable habitat.

Our alternative hypothesis (H2) predicted that specialist species, which are vulnerable to intensive management practices, would be less abundant in highly productive regions. We found limited support for this hypothesis. Indeed, although grassland specialist species richness decreased with increasing crop production, we observed an increase of arable specialist species richness along this gradient. Nevertheless, given the clarity of results reported in numerous smaller-scale studies (Chiron et al., 2014; Filippi-Codaccioni et al., 2010a; Jeliazkov et al., 2016; Newton 2004), and in spite of the positive relationship we observed between crop production and arable specialist species richness, we still believe arable specialist species to be vulnerable to intensive management practices. We suggest that this vulnerability could not be detected in our studies because we did not try to distinguish between the impacts of the extent of arable habitat and that of intensive management practices.

It is widely accepted that the increase of the community specialization index along a crop production gradient occurs because open habitat specialists replace generalist species. Our results show this is partially the case, as generalist species richness did decrease while arable specialist species richness increased along the crop production gradient. We also noted a decrease of grassland specialist species richness along the same gradient, in accordance with the results from Teillard et al. (2014). As all grassland specialists but one have a lower species specialization index than any arable specialist (Teillard et al., 2015), the increase of the community specialization index was also partly due to a shift from grassland specialists to arable specialists.

We observed a negative relationship between the community trophic index and crop production, which may be explained simply by the low species trophic index of arable specialist species, or perhaps by the scarcity of invertebrate food for birds in intensive croplands. Intensive management of cropland, such as insecticide use (Boatman et al., 2004) and removal or degradation of field margins (Wilson et al., 1999), has previously been found to reduce invertebrate abundance. The decline of invertebrate food for birds in intensive cropland has been observed repeatedly (Wilson et al., 1999) and requires birds to forage in 
a)

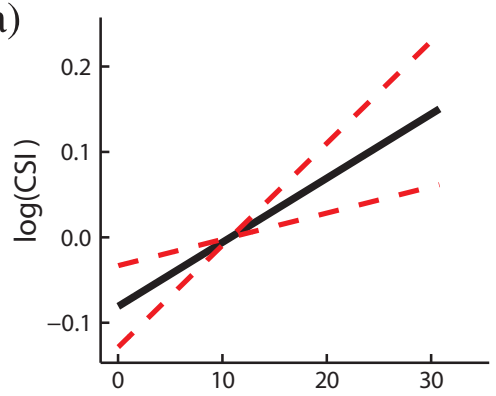

Crop production (gigacalha ${ }^{-1}$ )

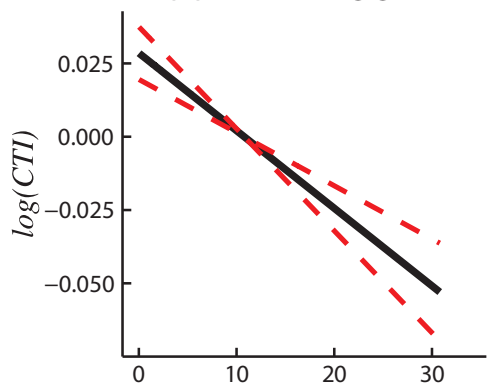

Crop production (gigacalh $\mathrm{a}^{-1}$ )

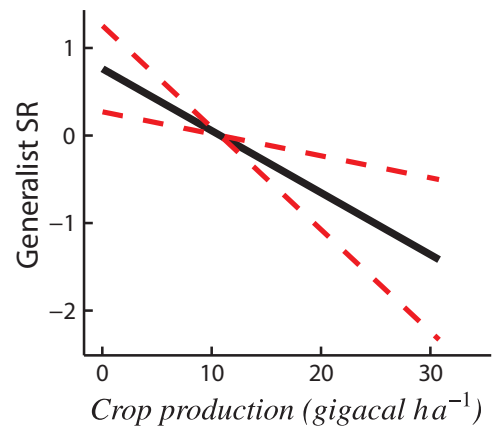

b)
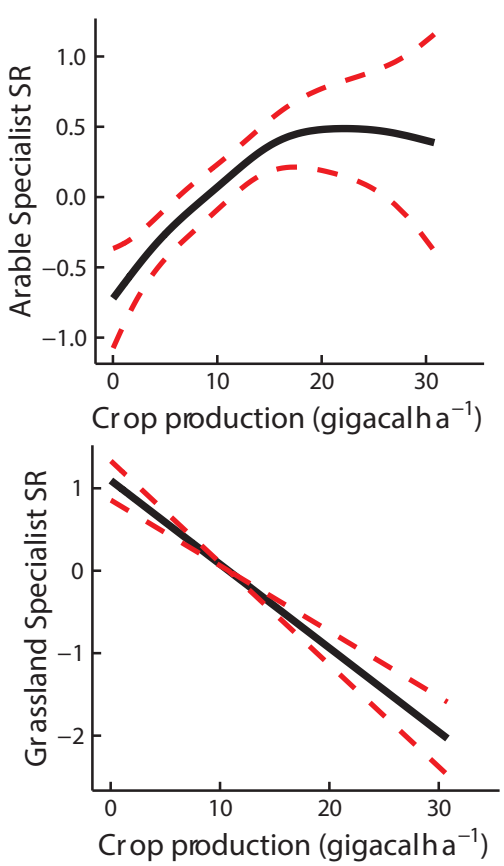

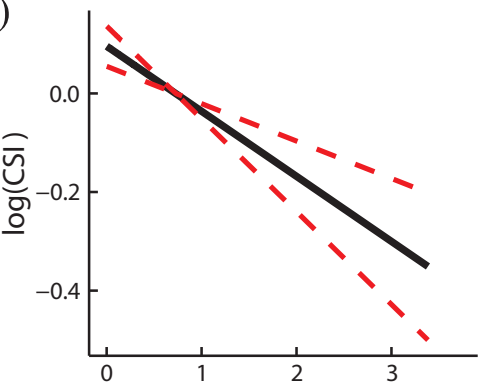

Livestock production (gigacal $h a^{-1}$ )

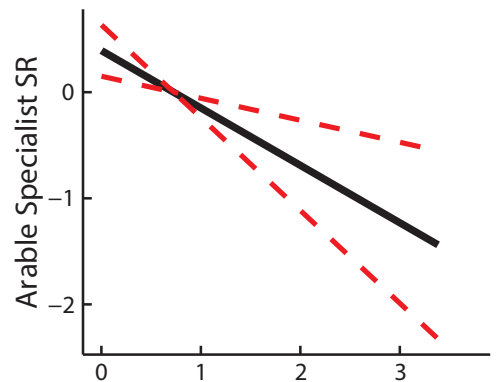

Livestock production (gigacal $\mathrm{ha}^{-1}$ )

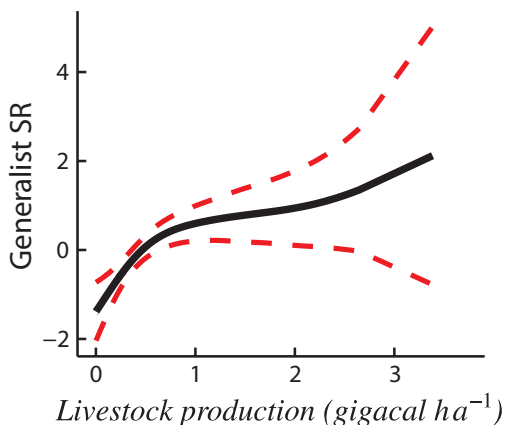

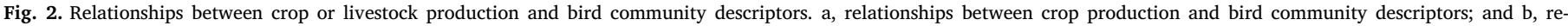

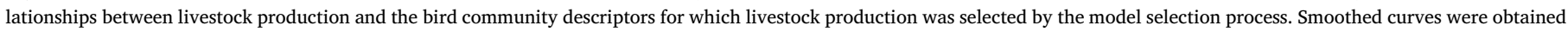

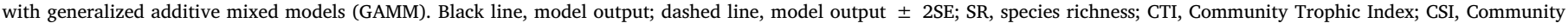
Specialization Index.

neighboring grasslands and hedgerows (Girard et al., 2012). Negative impacts of pesticides on insectivore bird populations have also been previously observed (Boatman et al., 2004; Hallmann et al., 2014).

\subsection{Livestock production and the homogenization of bird communities}

As described above, we observed a negative relationship between community specialization index or arable specialist species richness and livestock production, along with a concave relationship between generalist species richness and livestock production. For low levels of livestock production, the concave relationship was positive, but we did not have enough data to distinguish between a positive saturated or a hump-shaped relationship (Fig. 2b and Supplementary Figure D.2). These trends are consistent with functional biotic homogenization as described by Devictor et al. (2008). These authors described as functional biotic homogenization the rampant replacement of specialist species by generalist species and suggested the CSI as a particularly effective indicator for measuring this trend. They suggested that habitat specialists may be particularly vulnerable to both temporal disturbances and spatial heterogeneity, because they hardly make use of the various habitats in a heterogeneous landscape, and because they are not able to seek resources in neighboring undisturbed habitats following a temporal disturbance in their own habitat. Trends similar to the ones we observed can, therefore, be associated with either temporal disturbances, spatial heterogeneity, or both (Devictor et al., 2008), and do not make it possible to distinguish between the two phenomena. Given the negative relationship we observed between community specialization index and livestock production (Fig. 2b), along with the results of Devictor et al. (2008), it appears possible that the concave relationship we observed between generalist species richness and livestock production may have resulted from either higher spatial heterogeneity or from more disturbing management practices in the regions with the highest livestock production.

On the one hand, there is a case for attributing the observed trends to spatial heterogeneity. Indeed, livestock production may well favor spatial heterogeneity, because of the diversity of feed resources for livestock, which can include grass fodder, maize fodder, and crops (Devun and Guinot, 2012). Spatial heterogeneity is a well-recognized driver of biodiversity (Benton et al., 2003; Perović et al., 2015; Tscharntke et al., 2005) and is expected to increase the total number of species as it provides more niches, making it possible for more species to co-exist. Some studies have confirmed the proposed relationship in farmlands (Morelli, 2013). Furthermore, heterogeneity should decrease community specialization, as was observed by Devictor et al. (2008). Indeed, habitat generalists can find resources in various habitats within a heterogeneous landscape, so they can be expected to thrive in heterogeneous landscapes. Conversely, habitat specialists have been shown to be vulnerable to spatial heterogeneity (Filippi-Codaccioni et al., 2010b; Teillard et al., 2014).

On the other hand, the observed trends may be due to more 
disturbing management practices in the regions with the highest livestock production. Indeed, in France, those regions were characterized by intensive dairy production systems (Appendix A in Supplementary materials). Intensive management of grassland has been suggested to generate temporal disturbances and discontinuities in availability of resources (Sabatier et al., 2015). Mowing and grazing change resource availability both directly, since they remove potentially seed producing grass from the ecosystem, and indirectly, through the bottom-up effect of this loss on arthropod communities. High livestock densities directly impact ground-nesting bird species by trampling. Loss of plant diversity associated with intensive practices (Wilson et al., 1999) can cause fluctuation in the availability of seed resources since seeds will only be available when the dominant plant species is spreading seeds.

It is to be noted that, although we observed a decrease in the community specialization index and in arable specialist species richness along a livestock production gradient, we found no evidence of grassland specialist decline along this gradient.

\section{Conclusion}

Our research has shown that bird communities in highly producing SARs specializing in crops are species-poor and highly specialized, whereas bird communities in highly producing SARs specializing in grazing livestock husbandry show distinct signs of functional biotic homogenization. Given the nature of these results, it appears likely that SARs specialized in crop production or in extensive livestock production have the potential to be important for farmland bird conservation, and perhaps they should be the focus of policies protecting farmland birds. It is possible that populations of arable specialist bird species could be favored by policies targeting the enhancement of these bird populations in highly crop-producing SARs. Conversely, populations of grassland specialists may benefit by managing SARs specialized in extensive livestock husbandry for biodiversity and relying on the more productive dairy-specialized SARs for production. Thus, our research hints towards a land sharing strategy for cropland and a land sparing strategy for livestock husbandry to protect farmland birds.

\section{Compliance with ethical standards}

The authors declare that they have no conflict of interest.

\section{Acknowledgements}

We would like to warmly thank the hundreds of volunteers who took part in the national breeding bird survey (STOC EPS programme). We also thank Félix Teillard for the methodological insight and access to his $\mathrm{R}$ scripts, Vincent Marcus from the French Ministry for Agriculture and Food (MAA) for the valuable insight on agricultural statistics, Pierre Cantelaube, from ODR, for providing the data to test against our estimations, and Rodolphe Sabatier and Federico Morelli for their valuable comments on the first drafts. This work was supported by the "Investments d'Avenir" Programme overseen by the French National Research Agency (ANR) (LabEx BASC;ANR-11-LABX-0034). This work was also supported by the European Commission within the Seventh Framework Programme in the frame of RURAGRI ERA-NET under Grant Agreement no 235175 TRUSTEE (ANR- 13-RURA-000101 ). The authors only are responsible for any omissions or deficiencies. Neither the TRUSTEE project nor any of its partner organisations, any organisation of the European Union, or European Commission is accountable for the content of this research. The funding bodies had no role in the study design, data collection and analysis, preparation of the manuscript or decision to publish.

\section{References}

ANSES, 2013. Ciqual French Food Composition Table Version 2013. https://pro.anses.fr/ TableCIQUAL/index.htm. (Accessed June 25 2014).

Barton, K., 2014. MuMIn: Multi-model Inference. R Package Version 1.10.5.

Benton, T.G., Vickery, J.A., Wilson, J.D., 2003. Farmland biodiversity: is habitat heterogeneity the key? Trends Ecol. Evol. 18, 182-188. http://dx.doi.org/10.1016/ S0169-5347(03)00011-9.

Boatman, N.D., Brickle, N.W., Hart, J.D., et al., 2004. Evidence for the indirect effects of pesticides on farmland birds. Ibis 146, 131-143. http://dx.doi.org/10.1111/j.1474919X.2004.00347.x.

Chiron, F., Chargé, R., Julliard, R., et al., 2014. Pesticide doses, landscape structure and their relative effects on farmland birds. Agric. Ecosyst. Environ. 185, 153-160. http://dx.doi.org/10.1016/j.agee.2013.12.013.

Devictor, V., Julliard, R., Clavel, J., et al., 2008. Functional biotic homogenization of bird communities in disturbed landscapes. Glob. Ecol. Biogeogr. 17, 252-261. http://dx doi.org/10.1111/j.1466-8238.2007.00364.x.

Devun, J., Guinot, C., 2012. Alimentation des bovins: Rations moyennes et autonomie alimentaire. Institut de l'Elevage.

Donald, P.F., Gree, R.E., Heath, M.F., 2001. Agricultural intensification and the collapse of Europe's farmland bird populations. Proc. Biol. Sci. 268, 25-29. http://dx.doi.org/ 10.1098/rspb.2000.1325.

Donald, P.F., Sanderson, F.J., Burfield, I.J., van Bommel, F.P.J., 2006. Further evidence of continent-wide impacts of agricultural intensification on European farmland birds, 1990-2000. Agric. Ecosyst. Environ. 116, 189-196. http://dx.doi.org/10.1016/j. agee.2006.02.007.

Dormann, C.F., McPherson, J.M., Araújo, M.B., et al., 2007. Methods to account for spatial autocorrelation in the analysis of species distributional data: a review. Ecography 30, 609-628. http://dx.doi.org/10.1111/j.2007.0906-7590.05171.x.

Doxa, A., Paracchini, M.L., Pointereau, P., et al., 2012. Preventing biotic homogenization of farmland bird communities: the role of high nature value farmland. Agric. Ecosyst. Environ. 148, 83-88. http://dx.doi.org/10.1016/j.agee.2011.11.020.

Dross, C., Jiguet, F., Tichit, M., 2017. Concave trade-off curves between crop production and taxonomic, functional and phylogenetic diversity of birds. Ecol. Ind. 79, 83-90. http://dx.doi.org/10.1016/j.ecolind.2017.03.046.

FAO, 2003. Les bilans alimentaires - Manuel.

Filippi-Codaccioni, O., Devictor, V., Bas, Y., et al., 2010a. Specialist response to proportion of arable land and pesticide input in agricultural landscapes. Biol. Conserv. 143, 883-890. http://dx.doi.org/10.1016/j.biocon.2009.12.035.

Filippi-Codaccioni, O., Devictor, V., Bas, Y., Julliard, R., 2010b. Toward more concern for specialisation and less for species diversity in conserving farmland biodiversity. Biol. Conserv. 143, 1493-1500. http://dx.doi.org/10.1016/j.biocon.2010.03.031.

Girard, J., Baril, A., Mineau, P., Fahrig, L., 2012. Foraging habitat and diet of Song Sparrows (Melospiza melodia) nesting in farmland: a stable isotope approach. Can. J. Zool. 90, 1339-1350. http://dx.doi.org/10.1139/z2012-103.

Gregory, R.D., van Strien, A., 2010. Wild bird indicators: using composite population trends of birds as measures of environmental health. Ornithol. Sci. 9, 3-22.

Haberl, H., Erb, K.H., Krausmann, F., et al., 2007. Quantifying and mapping the human appropriation of net primary production in earth's terrestrial ecosystems. Proc. Natl. Acad. Sci. 104, 12942-12947.

Hallmann, C.A., Foppen, R.P.B., van Turnhout, C.A.M., et al., 2014. Declines in insectivorous birds are associated with high neonicotinoid concentrations. Nature 511, 341-343. http://dx.doi.org/10.1038/nature13531.

Jeliazkov, A., Mimet, A., Chargé, R., et al., 2016. Impacts of agricultural intensification on bird communities: new insights from a multi-level and multi-facet approach of biodiversity. Agric. Ecosyst. Environ. 216, 9-22. http://dx.doi.org/10.1016/j.agee. 2015.09.017.

Jiguet, F., Gadot, A.-S., Julliard, R., et al., 2007. Climate envelope, life history traits and the resilience of birds facing global change. Glob. Change Biol. 13, 1672-1684. http://dx.doi.org/10.1111/j.1365-2486.2007.01386.x.

Jiguet, F., Devictor, V., Julliard, R., Couvet, D., 2012. French citizens monitoring ordinary birds provide tools for conservation and ecological sciences. Acta Oecol. 44, 58-66. http://dx.doi.org/10.1016/j.actao.2011.05.003.

Julliard, R., Jiguet, F., Couvet, D., 2004. Common birds facing global changes: what makes a species at risk? Glob. Change Biol. 10, 148-154. http://dx.doi.org/10.1111/ j.1365-2486.2003.00723.x.

Krausmann, F., Erb, K.-H., Gingrich, S., et al., 2013. Global human appropriation of net primary production doubled in the 20th century. Proc. Natl. Acad. Sci. 110, 10324-10329. http://dx.doi.org/10.1073/pnas.1211349110.

Le Féon, V., Schermann-Legionnet, A., Delettre, Y., et al., 2010. Intensification of agriculture, landscape composition and wild bee communities: a large scale study in four European countries. Agric. Ecosyst. Environ. 137, 143-150. http://dx.doi.org/10. 1016/j.agee.2010.01.015.

Morelli, F., 2013. Quantifying effects of spatial heterogeneity of farmlands on bird species richness by means of similarity index pairwise. Int. J. Biodivers. e914837. http://dx. doi.org/10.1155/2013/914837.

Newton, I., 2004. The recent declines of farmland bird populations in Britain: an appraisal of causal factors and conservation actions. Ibis 146, 579-600. http://dx.doi.org/10. 1111/j.1474-919X.2004.00375.x.

Perović, D., Gámez-Virués, S., Börschig, C., et al., 2015. Configurational landscape heterogeneity shapes functional community composition of grassland butterflies. J. Appl. Ecol. 52, 505-513. http://dx.doi.org/10.1111/1365-2664.12394.

Perrins, C., Cramp, S., 1998. The Complete Birds of the Western Palearctic on CD-ROM. 
Oxford University Press.

Phalan, B., Onial, M., Balmford, A., Green, R.E., 2011. Reconciling food production and biodiversity conservation: land sharing and land sparing compared. Science 333, 1289-1291. http://dx.doi.org/10.1126/science.1208742.

Princé, K., Lorrillière, R., Barbet-Massin, M., Jiguet, F., 2013. Predicting the fate of French bird communities under agriculture and climate change scenarios. Environ. Sci. Policy 33, 120-132. http://dx.doi.org/10.1016/j.envsci.2013.04.009.

Princé, K., Lorrillière, R., Barbet-Massin, M., et al., 2015. Forecasting the effects of land use scenarios on farmland birds reveal a potential mitigation of climate change impacts. PLoS One 10, e0117850. http://dx.doi.org/10.1371/journal.pone.0117850.

Ramankutty, N., Evan, A.T., Monfreda, C., Foley, J.A., 2008. Farming the planet: 1. Geographic distribution of global agricultural lands in the year 2000. Glob Biogeochem Cycles 22http://dx.doi.org/10.1029/2007GB002952. (GB1003).

Sabatier, R., Durant, D., Hazard, L., et al., 2015. Towards biodiversity-based livestock systems: review of evidence and options for improvement. CAB Rev. Perspect. Agric. Vet. Sci. Nutr. Nat. Resour. 10, 1-13.

Sausse, C., Barbottin, A., Jiguet, F., Martin, P., 2015. Do the effects of crops on skylark (Alauda arvensis) differ between the field and landscape scales? PeerJ 3, e1097. http://dx.doi.org/10.7717/peerj.1097.

Storkey, J., Meyer, S., Still, K.S., Leuschner, C., 2012. The impact of agricultura intensification and land-use change on the European arable flora. Proc. R. Soc. Lond. B: Biol. Sci. 279, 1421-1429. http://dx.doi.org/10.1098/rspb.2011.1686.

Teillard, F., Antoniucci, D., Jiguet, F., Tichit, M., 2014. Contrasting distributions of grassland and arable birds in heterogenous farmlands: implications for conservation. Biol. Conserv. 176, 243-251. http://dx.doi.org/10.1016/j.biocon.2014.06.001.

Teillard, F., Jiguet, F., Tichit, M., 2015. The response of farmland bird communities to agricultural intensity as influenced by its spatial aggregation. PLoS One 10, e0119674. http://dx.doi.org/10.1371/journal.pone.0119674.

Tscharntke, T., Klein, A.M., Kruess, A., et al., 2005. Landscape perspectives on agricultural intensification and biodiversity - ecosystem service management. Ecol. Lett. 8, 857-874. http://dx.doi.org/10.1111/j.1461-0248.2005.00782.x.

Wickham, H., 2009. Ggplot2: Elegant Graphics for Data Analysis. Springer, New York. Wilson, J.D., Morris, A.J., Arroyo, B.E., et al., 1999. A review of the abundance and diversity of invertebrate and plant foods of granivorous birds in northern Europe in relation to agricultural change. Agric. Ecosyst. Environ. 75, 13-30. http://dx.doi.org/ 10.1016/S0167-8809(99)00064-X.

Wood, S.N., 2006. Generalized Additive Models: an Introduction with R. CRC Press, Boca Raton.

Zuur, A.F., Ieno, E.N., Walker, N., et al., 2009. Mixed Effects Models and Extensions in Ecology with R. Springer New York, New York, NY 